\title{
Sesame, Sweet Almond \& Sesame and Sweet Almond Oil for the Prevention of Striae in Primiparous Females: A Triple-Blind Randomized Controlled Trial
}

\author{
Jamileh Malakouti, ${ }^{1}$ Azizeh Farshbaf Khalili, ${ }^{2}$ and Atefeh Kamrani ${ }^{3,}{ }^{*}$ \\ ${ }^{1}$ Department of Midwifery, Faculty of Nursing and Midwifery, Tabriz University of Medical Sciences, Tabriz, IR Iran \\ ${ }^{2}$ Physical Medicine and Rehabilitation Research Centre, Faculty of Nursing and Midwifery, Tabriz University of Medical Sciences, Tabriz, IR Iran \\ ${ }^{3}$ Department of Midwifery, Faculty of Nursing and Midwifery, Tabriz University of Medical Sciences, Tabriz, IR Iran \\ "Corresponding author: Atefeh Kamrani, Department of Midwifery, Faculty of Nursing and Midwifery, Tabriz University of Medical Sciences, Tabriz, IR Iran. Tel: +98-9189609831, \\ Fax: +98-4134796969, E-mail: atykamrani@yahoo.com
}

Received 2015 October 11; Revised 2015 November 13; Accepted 2015 December 13.

\begin{abstract}
Background: Striae Gravidarum is a physiological skin change that many females experience during pregnancy and causes stress and concerns about their beauty, self-esteem and other psychological problems, by irritation and even ulcers in the affected areas. Objectives: This study was performed to evaluate the effect of sesame, sweet almond, and sesame and sweet almond oil on prevention of striae (primary outcome) in primiparous females.

Methods: This triple-blind randomized controlled clinical trial was done on 20018 to 35-year-old primiparous females at five governmental health clinics affiliated to Arak University of Medical Sciences, Iran. The subjects were allocated to three intervention groups and one control group by four and eight block randomization and allocation ratio of 1:1:1:1. The strategy used for analyzing data was intention to treat analysis. The intervention groups and control group received 1cc sesame, 1cc sweet almond and sesame oil, 1cc sweet almond oil, and 1cc Placebo, respectively, two times (1 mL twice daily without massaging the abdomen) for 20 weeks. One-way analysis of variance (ANOVA), chi-square, Kruskal-Wallis and binary logistic regression were used to analyze data.

Results: Striae at 35 to 38 weeks of pregnancy were observed in $59.2 \%, 16.7 \%, 14 \%$ and $82 \%$ of participants in sweet almond, sesame, sesame \& sweet almond oil and control groups, respectively $(\mathrm{P}<0.001)$. The occurrence risk of striae was significantly decreased in the sesame (adjusted $\mathrm{OR}=0.04, \mathrm{CI}=0.01$ to 0.13 ), sweet almond $(0.27,0.10$ to 0.72 ), and sesame \& sweet almond oil (adjusted OR= $0.03, \mathrm{CI}=0.01$ to 0.10$)$ groups, compared with the control group. Abdominal itching was significantly different $(\mathrm{P}<0.001)$ among consumers of sweet almond (65.3\%), sesame (10.5\%), sesame \& sweet almond oil (44\%), and control group (78\%).

Conclusions: The sesame oil, sweet almond oil and their combination was effective in reducing the occurrence of abdominal steriae and its itching.
\end{abstract}

Keywords: Striae Gravidarum, Primiparous Females, Sweet Almond, Sesame Oil

\section{Background}

Striae Gravidarum (SG) is a physiological skin change that many females experience during pregnancy $(1,2)$ that can commonly be seen after 24 weeks of pregnancy in forms of pink or red ribbons (3) and sometimes as congested areas in the skin of the abdomen, buttocks, breasts, hips and Thighs $(4,5)$. These lesions change into silvery scars, and slightly sunken and wrinkled lines remain postpartum (6). The cause of steriae is not yet fully known, however it is linked with changes in tensile strength and elasticity of the skin structures. Mechanical stretching of the skin associated with hormonal factors have been proposed in the pathogenesis of these lesions (7-9). Steriae is also created under the effect of changes in connective tissue that involves elastin and fibrin reduction in the skin (10). The data on prevalence of SG and the risk factors associated with its development are scant and often contradictory. It has been estimated that up to $90 \%$ of pregnant females develop SG, however, some studies report the prevalence to be as low as 50\% (11). Proposed risk factors for the development of SG include family history, race, skin type, birth weight, baseline body mass index (BMI), age, weight gain and poor nutrition, however most of these have not been substantiated $(2,8,12)$.

Although striae is not considered to be a lifethreatening factor yet it causes stress and concerns about beauty, self-esteem and other psychological problems by irritation and even ulcers in the affected areas $(13,14)$. Severe stress during pregnancy causes negative effect on fetal brain development that brings up unusual behaviors at the age of 14 to 15 (15). The severe form of SG, as well as other skin conditions, affect the emotions of the pregnant females. Research suggests that some emotional

Copyright @ 2016, Iranian Red Crescent Medical Journal. This is an open-access article distributed under the terms of the Creative Commons Attribution-NonCommercial 4.0 International License (http://creativecommons.org/licenses/by-nc/4.0/) which permits copy and redistribute the material just in noncommercial usages, provided the original work is properly cited. 
problems of females during pregnancy and after delivery are traces of the remaining striae in different parts of their body (16). Striae, especially on the belly, causes concern for pregnant and parturient females. Most of these females are looking for different treatments (13). There is currently no treatment modality that is consistently effective with minimal adverse effects (17). Most adverse effects, particularly with laser, occur in patients with darker skin types, although most of these treatments are not effective $(18,19)$. These factors have driven primiparous females deciding to become pregnant to search for items affecting the creation of striae and ways to prevent or treat it (11). Several treatments have been proposed, yet no effective modality is available yet (20). Some authors, have suggested that giving time is the only treatment for striae so that the skin returns to its normal appearance over years but nowadays it has been suggested that effective treatment of striae should be started during the active stage before the scarring process is complete (21).

One of the traditional preventive measures of striae is using local lubricants and some reports have mentioned the success of some of these methods. Creams, lotions and ointments are used by up to $78 \%$ of pregnant females, yet have significant costs $(22,23)$. Some unconventional therapies and anecdotal reports recommended using unproven oils and natural remedies for striae. The underlying principle for this use would probably keep the skin well hydrated. Sweet almond oil, wheat germ oil, olive oil, avocado oil, castor oil and applying seaweed wraps have these properties (24).

Considering the availability, low cost and easy use of oils and due to the lack of trials concerning the effect of sesame and sweet almond oil on prevention of striae in primiparous females, this study was carried out to address this gap in knowledge.

\section{Objectives}

This study aimed to evaluate the effect of sesame, sweet almond, and sesame \& sweet almond oil on prevention of striae in primiparous females.

\section{Methods}

\subsection{Type of Study and Participants}

This triple-blind (blinding the participants, data collectors and data analyzers) randomized controlled clinical trial was done on 200 primiparous females aged 18 to 35 years old at five governmental health clinics affiliated to Arak University of Medical Sciences, Iran. Arak is one of the major industrial cities of Iran. It has a tropical climate that is in general cold and dry. Persian people are the only native population in Arak. According to the 2006 census, its population was 526182 with 160761 families. Participants' recruitment was carried out from 22.8.2014 to 20.12.2014 and follow-up ended on 24.02.2015. Criteria for inclusion consisted of: being primiparous, age of 18 to 35 years, age of pregnancy 16 to 20 weeks, a single live fetus, no previous striae, general health and no chronic diseases, according to the patient's comments, body mass index of 19.8 to 26 , having literacy to read and write, having no history of allergy to material of this study, having time and ability to use oils two times a day. Exclusion criteria were using any kind of herbal or chemical medicines on the affected area, polyhydramnios, adrenal gland disease, surgical scar on the abdomen and skin diseases. The researcher assessed all primiparous females aged 18 to 35 years, based on eligibility criteria at the selected governmental health clinic, and if they met the criteria, a written informed consent was obtained from them.

Sample size was calculated as 45 individuals in each group based on information obtained from the study of Behnia et al. (25) using the Pocak formula, and regarding initial information on the percentage of severe striae in both sweet almond \& glycerin oil by considering $\mathrm{p}_{1}=34 \%$ and $\mathrm{p}_{2}=7.5 \%, \beta=0.2, \alpha=0.05$ with $10 \%$ possible dropout rate, it was considered as 50 samples for each group (Figure 1).

\subsection{Sampling}

In order to sample, this city was divided to five regions: north, south, east, west and centre, then a governmental health clinic was randomly selected from each region. Sampling was started after obtaining approval from the research deputy of Tabriz University of Medical Sciences and the Ethics Committee of this university (ethic code: 9290). Also, the research was registered in the Iranian registry of clinical trials with the following code IRCT201208048170N3.

Five governmental health centers affiliated to Arak University of Medical Sciences were the research setting, including Abooreihan, Arastoo, Jahangiri, Nateghi, Hazrate, Zeinabe Kobra Arak-Iran.

\subsection{Randomization and Intervention}

Qualified subjects were assigned to four groups (three received the sesame oil or almond oil or the combination of sesame-almond oil and the control group received the placebo) using block randomization with four and eight blocks and allocation ratio of 1:1:1:1. Similar glasses of oil or placebo were stored and sealed in opaque envelops with sequential numbers from 1 to 200 by a person other than 


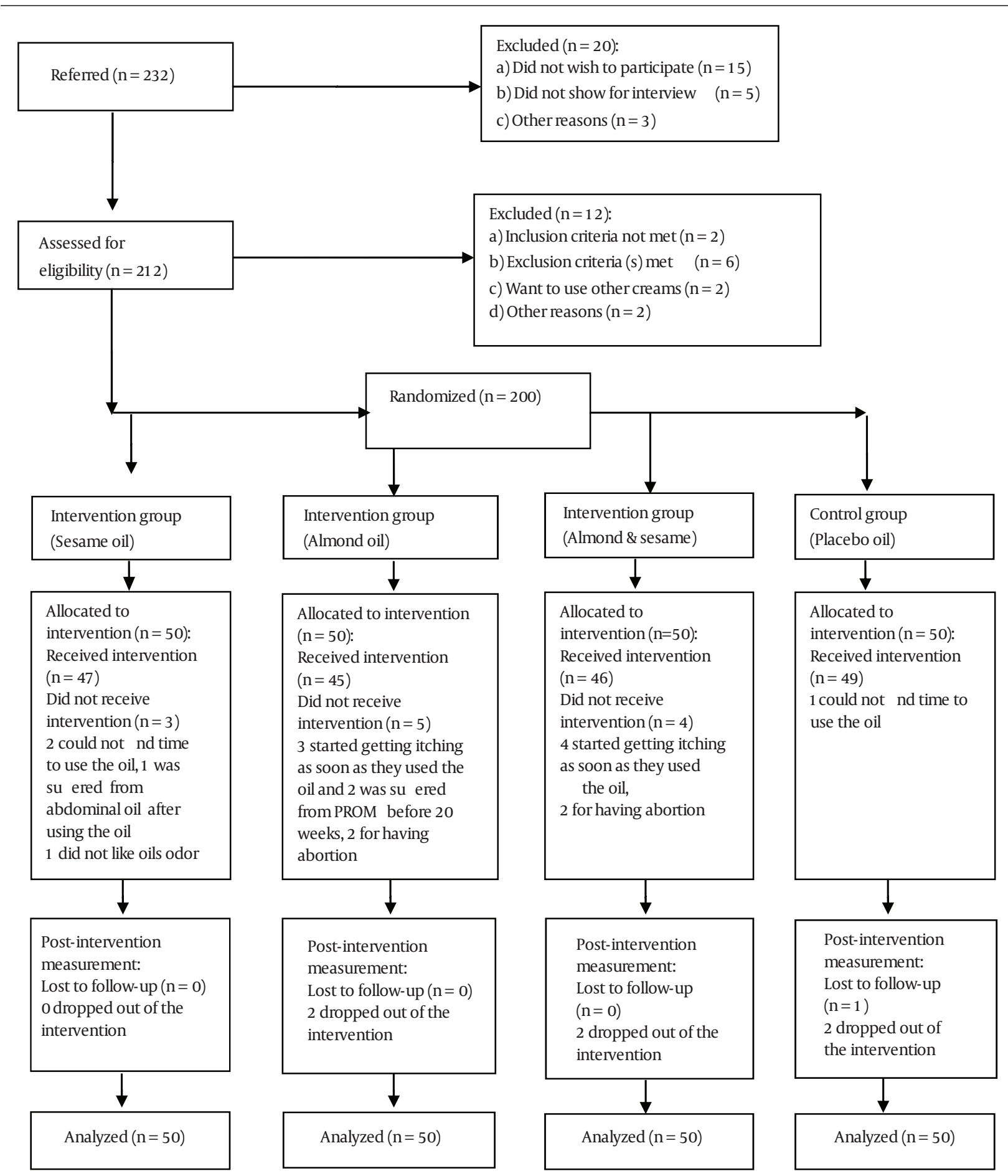

Figure 1. Flowchart of Participants' Progress Through the Phases of the Trial

the researcher. Oils and Placebo were provided with totally same appearance (smell, color and shape).

For the preparation of the drugs, $60 \mathrm{~mL}$ of sesame oil with purity of $95 \%$ was obtained directly from the Barij essence pharmaceutical company, and $60 \mathrm{~mL}$ sweet almond oil with purity of $95 \%$ was obtained directly from 
the Mahdaroo Pharmaceutical company (mentioned pharmaceutical companies were marked with a national standard for pure products). Next, combination of $30 \mathrm{~mL}$ of sesame oil and $30 \mathrm{~mL}$ of sweet almond oil were poured in appropriate tubes. To prepare the placebo, $15 \mathrm{~mL}$ of cellulose lubricant gel was added to $55 \mathrm{~mL}$ of distilled water and was poured in the appropriate tube. Labels of the original drugs and placebo were prepared similarly. Intervention and control groups received $1 \mathrm{~mL}$ of sesame, 1 $\mathrm{mL}$ of sweet almond, $1 \mathrm{~mL}$ of sesame \& sweet almond oil and $1 \mathrm{~mL}$ of Placebo, respectively, two times $(1 \mathrm{~mL}$ twice daily without massaging the abdomen) for 20 weeks (six glasses, each glass contained $60 \mathrm{~mL}$ of sesame, sweet almond, sesame \& sweet almond or placebo oil). The first person recieved package 3 including: three glasses with a 2-mL syringe and for second person envelope 2; consequently until 200 was completed. To ensure the application of oils, participants were reminded that after submitting three used glasses jars, at 32 weeks the other three empty glasses should be returned. All oils were made at the faculty of Tabriz pharmacy, so neither the mother nor the researchers were aware of their contents. The study analyzer was also blind. The participants were advised to contant the researcher immediately in case of any complications. The telephone of the researcher was given for necessary contact.

\subsection{Data Collection Tool}

In this study, socio-demographic and obstetrics characteristics form, including questions about age, wife and husband educational level, gestational age, job, height, weight, abortion history, weight gain at pregnancy, birth weight and gender of newborn were filled before the intervention. Davey (7) and Dhiman (26) methods and complication checklist were used as data gathering tools.

Assessment was done on the basis of subjective and objective criteria. Evaluated parameters for measuring the intensity of striae were severity of striae and itching. The Davey method was used as follows: the abdomen was divided to four parts with a vertical and a horizontal line (right, left, upper and lower quadrants) and each section received a score of 0 for no striae, grade 1 for average number of striae, and grade 2 for many striae. The total score was from 0 to 8 . Intensity of striae was assessed in three groups: no striae, $(1-2)$ moderate striae and (3 - 8) severe striae (7). For evaluating the intensity of itching, the Dhiman method was used, so that these parameters were graded from 0 to 4 according to severity as follows: 0 indicated no itching (normal activities); 1 mild itching (to 21 times/day); 2 moderate itching ( 4 to-3 time/day, but not disturbing routine work); 3 severe itching (6 to5 times/day, disturbing routine work) and 4 very severe itching (throughout the day, disturbing routine work and sleep). Thus, a score of 0 indicated no itching and maximum score of 4 showed very severe itching (26).

Content and face validity were used to determine the validity of check lists and questionnaire in this study. Check lists and questionnaire were given to ten faculty members and after gathering their views, necessary modifications were done on the forms based on obtained feedback. Davey and Kaman methods have not been validated specifically for striae but as other researchers have used these methods in their articles, they were also used in this study. Three observers simultaneously observed the reliability of the method. Due to the subjective and objective criteria, assessment was done at the end of 35 to 38 weeks of pregnancy, by three midwives, who had been trained for evaluating these parameters by the researchers. They were unaware of the type of intervention. To determine the reliability of this method for evaluating the severity of steriae and itching, the Fleiss Kappa coefficient was used for agreement among two or more evaluators using the STATA 12 software, which was 0.97 and 0.89 , respectively, for severity of striae and itching showing high levels of favorable agreement among evaluators.

\subsection{Data Analysis}

Data was analyzed using the SPSS version13 software. The independent $t$ and chi-square tests for trend were used to compare the socio-demographic and obstetric characters of groups. The Kruskal-Wallis test was used to compare the incidence and severity of SG and itching between the groups. For comparison of steriae, binary logistic analysis was used by adjusting baseline values and potential confounding variables. The level of significance was considered 0.05 at all stages.

\section{Results}

Participants recruitment was carried out from 22.8.2014 to 20.12.2014 and follow-up ended on 24.02.2015. A total of 232 patients were initially screened, yet 32 were excluded because of ineligibility or lack of interest in participation in the study. Thus, 50 participants were allocated to each group. Finally, all participants were followed until the end of 5 to 38 weeks of pregnancy. There was no statistically significant difference between the four groups in terms of socio-demographic characteristics such as age, education level, skin type, history of SG among first-degree relatives, water and vegetable consumption, sport history, and obstetrics characteristics.

The average age of females was 24.9 (3.9) years. About half of the studied participants had high school education, 
olive skin, and more than two-thirds of them had history of first-degree relative with striae. The mean (SD) weight gain during pregnancy in the sweet almond oil, sesame oil, sesame \& sweet almond oil and control group were 13.9 (4.4), 13.0 (5.5), 14.7 (4.8) and 13.6 (4.1), respectively ( $\mathrm{P}=0.37)$

There was a significant difference in terms of education level, spouse education level, income adequacy and job between groups. The other general characteristics were similar in the four groups (Table 1 ).

The occurrence of striae at 35 to 38 weeks of pregnancy was 59.2\% among consumers of sweet almond oil, $16.7 \%$ in the sesame oil, $14 \%$ in the sesame \& sweet almond oil and $82 \%$ in the control group. The Kruskal-Wallis test showed significant differences between the study groups $(\mathrm{P}<0.001)$. Post Hoc Tukey test showed that with the exception of sesame and sesame-sweet almond oil, other groups had pairwise significant differences $(\mathrm{P}<0.001)$ (Table 2$)$. The rate of mild striae among sweet almond oil consumers was $40.8 \%$ and severe was $18.4 \%$. Mild striae among sesame oil group was $16.8 \%$ and there were no severe striae among this group. The rate of mild striae among sweet almond -sesame oil group was $10 \%$ and severe striae among this group was $4 \%$, while mild striae among the placebo group was $22 \%$ and severe striae in this group was $60 \%$.

Abdominal itching among consumers of almond oil, sesame oil, sesame \& sweet almond oil and control group were $65.3 \%, 10.5 \%, 44 \%$ and $78 \%$, respectively. Sesame oil consumers did not experience severe and very severe form of itching, while this was found in $34.7 \%$ of almond oil consumers $(\mathrm{P}<0.001)$ (Table 2$)$.

In the present study, all interventions (sweet almond oil, sesame oil, and sesame \& sweet almond oil) significantly decreased the occurrence of striae compared to the control group, so that after adjustment for confounding variables, the risk of striae in sesame oil group $(\mathrm{OR}=0.04$, $\mathrm{CI}=0.01$ to 0.13 ) was $96 \%$ less than the placebo group. Use of almond oil ( $\mathrm{OR}=0.27,95 \% \mathrm{CI}=0.10$ to 0.72$)$ decreased the risk of striae to $27 \%$ compared to the control group. Also, the risk of striae in sesame oil \& sweet almond oil group $(\mathrm{OR}=0.03, \mathrm{CI}=0.01$ to 0.10$)$ was $97 \%$ less than the placebo group (Table 3 ).

Abdominal itching decreased significantly among consumers of sesame oil and sesame \& sweet almond oil compared to the placebo group after adjustment for confounders. The risk of itching in the sesame oil group (OR= $0.03, \mathrm{CI}=0.01$ to 0.10$)$ was $97 \%$ less than the placebo group. Itching risk $(\mathrm{OR}=0.18, \mathrm{CI}=0.07$ to 0.47 ) decreased to $82 \%$ in the sesame \& sweet almond oil compared to the placebo group (Table 4). However, binary logistic regression adjusted for confounders didn't show a significant difference between sweet almond oil and control group in terms of abdominal itching.

\section{Discussion}

The results of the present study indicated that using sweet almond oil, sesame oil, and their combination was effective in reducing the incidence of abdominal striae and itching compared to control oil. One of the strengths of this research was that nobody in the sesame oil group had severe striae and severe or very severe itching. The severity of striae was reduced among sweet almond oil group in comparison with the placebo group (59.2\%). Behnia and Hosseini (25) studied the effect of almond oil and glycerin on prevention of SG. In their study, the rate of severe striae in the placebo group was reported as $39 \%$, glycerin group 9.4\% and almond oil group 7.5\%. Thus, there was a significant difference among placebo and intervention groups ( $\mathrm{P}$ $<0.01)$. Our findings coincided with their results.

We didn't find any studies about the effect of sesame oil on prevention of SG, but a research by Kamini and Manjusri on 30 primiparous and multiparous females in the late second trimester of pregnancy by following two groups (15 patient in each group): 1-preventing group (without striae) and 2- curative group (with history of striae), showed that using Karaveer taila oil (including Karaveer leaf and sesame oil) during pregnancy on the abdomen relieved itching and changed the color and reduced the size of stretch marks without any side-effects $(P<0.001)(26)$. The results of this study was compatible with our study but in their study sesame oil was used in combination with Karaveer leaf, the number of participants was too low and the samples were not homogenized thus the results can't be generalized to the entire community.

A study was done by Timur Tashan and Kafkasli in 2010 on 141 primiparous females in Turkey, which were allocated to three groups one group received almond oil, the other one 15-minute massage sessions and the third group received bitter almond oil with massage on the abdomen. Their findings showed that using bitter almond oil had no effect on prevention of SG in comparison with the placebo group $(\mathrm{P}<0.001)(27)$. Their results were not consistent with our outcome. In their study, the process of blinding was not possible, so participants could change their behavior and so this could have influenced their outcome.

A study done by Taavoni et al. on 90 pregnant females in their second trimester of pregnancy with the following title "The Effect of Olive Oil and Saj Cream in Prevention of SG in 2009", showed that Saj cream containing lanolin, stearin, trietanolamine, almond oil and glycerin amide reduced the appearance of striae. In this study the occurrence of striae among consumers of Saj cream, olive oil and placebo was $16.7 \%, 40 \%$ and $56 \%$, respectively. The results showed that using olive oil was not effective on prevention of striae (28). 
Table 1. General Characteristics of the Participants in the Study Groups ${ }^{\mathrm{a}}$

\begin{tabular}{|c|c|c|c|c|c|}
\hline Characterstics & Sweet Almond Oil $(\mathbf{n}=\mathbf{5 0})$ & Study Groups Sesame oil $(n=50)$ & Sesame \& Sweet Almond Oil $(\mathbf{n}=\mathbf{5 0})$ & $\operatorname{Control}(\mathbf{n}=\mathbf{5 0})$ & PValue \\
\hline Age, $y$ & $24.9(3.8)$ & $24.3(4.4)$ & $24.7(3.5)$ & $25.3(4.1)$ & $0.62^{\mathrm{b}}$ \\
\hline $18-24$ & $21(42.8)$ & $23(47.9)$ & $24(48)$ & $29(59.2)$ & \\
\hline $30-35$ & $4(8.2)$ & $7(14.6)$ & $4(8)$ & $16(12.2)$ & \\
\hline Education level & & & & & $0.008^{\mathrm{d}}$ \\
\hline Primary & $1(2)$ & $1(2)$ & $1(2)$ & $3(6)$ & \\
\hline Secondary & $5(10)$ & $3(6)$ & $4(4)$ & $11(22)$ & \\
\hline High school diploma & $25(50)$ & $25(50)$ & $19(38)$ & $20(40)$ & \\
\hline Collegiate & $15(30)$ & $21(42)$ & $26(52)$ & $16(32)$ & \\
\hline Spouse education level & & & & & 0.04 \\
\hline Primary & $3(6)$ & $2(4)$ & $2(4)$ & $4(8)$ & \\
\hline Secondary & $10(20)$ & $6(12)$ & $6(12)$ & $10(20)$ & \\
\hline High school diploma & $23(46)$ & $27(54)$ & $20(40)$ & $24(48)$ & \\
\hline Collegiate & $14(28)$ & $14(28)$ & $22(44)$ & $12(24)$ & \\
\hline Job & & & & & $0.03^{\mathrm{c}}$ \\
\hline Housewife & $49(98)$ & $47(94)$ & $49(98)$ & $43(85.7)$ & \\
\hline Employed & $1(2)$ & $3(6)$ & $1(2)$ & $7(14.3)$ & \\
\hline Income & & & & & $0.01^{\mathrm{d}}$ \\
\hline Adequate & $7(14)$ & $12(24)$ & $13(26)$ & $19(38.8)$ & \\
\hline Relatively Adequate & $33(66)$ & $33(66)$ & $34(68)$ & $25(51)$ & \\
\hline Inadequate & $10(20)$ & $5(10)$ & $3(6)$ & $5(10.2)$ & \\
\hline BMI & $23.2(1.3)$ & $22.9(1.6)$ & $22.8(1.6)$ & $23.2(1.5)$ & $0.69^{\mathrm{b}}$ \\
\hline History of abortion & $9(18)$ & $10(20)$ & $10(20)$ & $10(20)$ & $0.99^{\mathrm{C}}$ \\
\hline Unwanted pregnancy & $5(10)$ & $4(8)$ & $4(8)$ & $3(6)$ & $0.86^{\mathrm{C}}$ \\
\hline Skin type & & & & & $0.06^{\mathrm{C}}$ \\
\hline White & $18(36)$ & $21(42.9)$ & $17(34)$ & $12(24)$ & \\
\hline The history of Steriae in first degree relatives & $41(82)$ & $42(84)$ & $36(72)$ & $39(79.6)$ & $0.68^{\mathrm{C}}$ \\
\hline Gender of the fetus & & & & & $0.35^{c}$ \\
\hline Boy & $29(58)$ & $30(61.2)$ & $23(46)$ & $24(48)$ & \\
\hline Girl & $21(42)$ & $19(38.8)$ & $27(54)$ & $26(52)$ & \\
\hline Daily consumption of water & & & & & $0.61^{\mathrm{d}}$ \\
\hline Less than 8 glasses & $33(66)$ & $37(75.5)$ & $37(74)$ & $41(82)$ & \\
\hline Between 8 and 10 glasses & $14(28)$ & $9(82)$ & $11(22)$ & $6(12)$ & \\
\hline More than 10 glasses & $3(6)$ & $3(6.1)$ & $2(4)$ & $3(6)$ & \\
\hline Vegetable \& fruit intake & & & & & $0.83^{\mathrm{d}}$ \\
\hline Less than 3 unit/day & $21(42)$ & $22(44.9)$ & $23(46)$ & $27(54)$ & \\
\hline Between 3-6/day & $26(52)$ & $26(53.1)$ & $24(48)$ & $21(42)$ & \\
\hline More than 6/day & $3(6)$ & $1(2)$ & $3(6)$ & $2(4)$ & \\
\hline Doing exercise & $18(36)$ & $21(42.9)$ & $15(30)$ & $21(42)$ & $0.51^{\mathrm{C}}$ \\
\hline Having constipation & $18(36)$ & $15(30)$ & $17(34)$ & $12(24)$ & $0.59^{c}$ \\
\hline
\end{tabular}

In the present study, the occurrence of striae was $59.2 \%$ among sweet almond oil consumers, so that only $40.8 \%$ of them experienced moderate and $18.4 \%$ severe form of striae. In this group, $65.3 \%$ of the participants had a degree of abdominal itching; $14.3 \%$ of them had itching throughout the day, disturbing their routine work and sleep and only $34.7 \%$ did not report irritation of the abdomen, while the occurrence of striae among consumers of sesame oil 
Table 2. Comparison of the Occurrence of Steriae and Itching in the Study Groups ${ }^{\mathrm{a}}$

\begin{tabular}{|c|c|c|c|c|c|}
\hline \multirow[b]{2}{*}{ Variables } & \multicolumn{4}{|c|}{ Study Groups } & \multirow[t]{2}{*}{ P Value $^{\text {b }}$} \\
\hline & Sweet Almond Oil $(\mathbf{n}=\mathbf{5 0})$ & Sesame Oil $(n=50)$ & Sesame \& Sweet Almond Oil $(n=50)$ & $\operatorname{Control}(\mathbf{n}=\mathbf{5 0})$ & \\
\hline Steriae & & & & & $<0.001$ \\
\hline No Steriae & $20(40.8)$ & $40(83.3)$ & $43(86)$ & $9(18)$ & \\
\hline Moderate & $20(40.8)$ & $8(16.7)$ & $5(10)$ & $11(22)$ & \\
\hline Severe & $9(18.4)$ & 0 & $2(4)$ & $30(60)$ & \\
\hline Itching & & & & & $>0.001$ \\
\hline No itching & $17(34.7)$ & $43(89.5)$ & $28(56)$ & $11(22)$ & \\
\hline Mild & $12(24.5)$ & $3(6.3)$ & $14(28)$ & $9(18)$ & \\
\hline Moderate & $3(6.1)$ & $2(4.2)$ & $6(12)$ & $10(20)$ & \\
\hline Severe & $10(20.4)$ & 0 & $1(2)$ & $13(26)$ & \\
\hline Very severe & $7(14.3)$ & 0 & $1(2)$ & $7(14)$ & \\
\hline
\end{tabular}

was reported as $16.7 \%$ (degree of average striae). The itching in this group was $10.4 \%$, so the $89.6 \%$ of this group did not report any itching. The effect of combination of sesame and sweet almond oil on prevention of striae was higher than the other groups. It is recommended for midwives to recommend the use this oil to their patients for the prevention of striae and itching at pregnancy and do further research in this area and other herbal oils.

There was no significant difference among placebo and intervention groups in terms of side effects including abdominal redness and itching, abdominal pain and rash, however three females $(4.1 \%)$ in the sweet almond oil group experienced redness. One female (2\%) in the sweet almond-sesame oil group and one (2\%) in placebo and six (21.2\%) in sweet almond group experienced redness, also one case (2\%) in the sweet almond-sesame oil experienced hirsutism. There was no report of side effects in the sesame oil group.

The strengths of this study include its innovation in examining the effect of sesame oil solely and in combination with sweet almond oil in pregnant females, which had not been done before, and without causing any serious adverse effects on the mother and the infant. The other strong point of this study was the use of placebo oil for the first time by the research group with the same color and consistency of other oils so that none of the females in the placebo group could realize that they had been in the placebo group. We obtained informed consent, so that in our study, sample attrition and loss to follow up was very low. We evaluated striae severity by three trained observers for correct implementation of reliability. There was no loss of participants because our strat- egy for analyzing data was intention to treat analysis and all participants were included in the groups to which they were allocated, whether or not they received the intervention given to their group (three women in sesame oil, six women in sweet almond oil, two women in sesame-sweet almond oil group could not receive their interventions). We did not exclude the participants from the study and followed up them throughout the study period. We used all principles of clinical trials in prevention of probable biases (blinding the participants, data collectors, and data analyzers completely), and because of recording three telephone numbers and two addresses from participants, we only had one loss to follow up. The limitations of this study included long term follow up (20 weeks) and large number of samples, which was at times fatigues for researchers, and due to lack of evaluation tools for itching, all responses given by mothers were supposed as the correct answer, so the researchers did not ensure of the accuracy of the given answers. Due to differences between the smell of sesame oil and almond oil, a few samples could guess the type of their interventions. Because of the effectiveness of sesame oil on prevention of SG, it is suggested for a study to be performed to assess the effect of this oil on improvement of striae after delivery, or otherwise statistical studies on other populations such as females, who want to lose weight and are concerned about the appearance of striae on their body, should be performed. Relatively small sample size with different ethnicity means the results cannot be generalized, and there is a need for further investigations in this area. 
Table 3. The Results of Binary Logistic Regression for Occurrence of Steriae

\begin{tabular}{|c|c|c|c|}
\hline Variable & Number & Adjusted OR $(95 \% \mathrm{CI})^{\mathrm{a}}$ & PValue \\
\hline \multicolumn{4}{|l|}{ Intervention } \\
\hline Placebo & 50 & Ref & $<0.001$ \\
\hline Sweet almond & 50 & $0.27(0.10$ to 0.72$)$ & 0.01 \\
\hline Sesame & 50 & 0.04 (0.01 to 0.13$)$ & $<0.001$ \\
\hline $\begin{array}{l}\text { Sesame \& Sweet } \\
\text { almond }\end{array}$ & 50 & 0.03 (0.01 to 0.10$)$ & $<0.001$ \\
\hline \multicolumn{4}{|l|}{ Education level } \\
\hline Collegiate & 79 & Ref & 0.87 \\
\hline Primary & 6 & $0.84(0.08$ to 8.80$)$ & 0.89 \\
\hline Secondary & 27 & 1.15 (0.31 to 4.31$)$ & 0.83 \\
\hline $\begin{array}{l}\text { High school \& } \\
\text { diploma }\end{array}$ & 88 & 1.39 (0.57 to 3.42$)$ & 0.47 \\
\hline Job & & & 0.48 \\
\hline Employed & 13 & Ref & \\
\hline Housewife & 187 & $1.85(0.34$ to 10.19$)$ & \\
\hline \multicolumn{4}{|l|}{ Income } \\
\hline Inadequate & 23 & Ref & 0.26 \\
\hline Sufficient & 51 & 0.67 (0.18 to 2.53$)$ & 0.56 \\
\hline $\begin{array}{l}\text { Relatively } \\
\text { Adequate }\end{array}$ & 126 & $1.45(0.47$ to 4.49$)$ & 0.52 \\
\hline \multicolumn{4}{|l|}{ Spouse education level } \\
\hline Collegiate & 63 & Ref & 0.89 \\
\hline Primary & 11 & $1.34(0.20$ to 8.75$)$ & 0.76 \\
\hline Secondary & 32 & $0.97(0.26$ to 3.47$)$ & 0.96 \\
\hline $\begin{array}{l}\text { High school \& } \\
\text { diploma }\end{array}$ & 94 & $1.34(0.52$ to 3.39$)$ & 0.54 \\
\hline
\end{tabular}

${ }^{\text {a }}$ Adjusted OR (95\%CI): adjusted odds ratio (95\% confidence interval).

\subsection{Conclusions}

The findings of this study indicated that application of sesame oil as well as combination of sesame and sweet almond oil during pregnancy was effective in reduction of SG. Thus, it is recommended for midwives to use this oil in the prevention of itching caused by striae during pregnancy and further research needs to be done in this area with other herbal oils to investigate the impact of other herbal medicines on reducing SG. However, this drug should only be used following the guidance of a qualified practitioner.

\section{Acknowledgments}

This research was part of a midwifery MSc thesis of Tabriz Nursing and Midwifery school. Hereby, the authors appreciate the financial support of research deputy
Table 4. The Results of Logistic Regression for Incidence of Itching

\begin{tabular}{|c|c|c|c|}
\hline Variable & Number & Adjusted OR $(95 \% C I)^{a}$ & PValue \\
\hline \multicolumn{4}{|l|}{ Intervention } \\
\hline Placebo & 50 & Ref & $<0.001$ \\
\hline Sweet almond & 50 & 0.44 (0.17 to 1.13$)$ & 0.09 \\
\hline Sesame & 50 & 0.03 (0.01 to 0.10$)$ & $<0.001$ \\
\hline $\begin{array}{l}\text { Sesame \& Sweet } \\
\text { almond }\end{array}$ & 50 & 0.18 (0.07 to 0.47$)$ & $<0.001$ \\
\hline \multicolumn{4}{|l|}{ Education level } \\
\hline Collegiate & 79 & Ref & 0.43 \\
\hline Primary & 6 & $0.42(0.05$ to 3.61$)$ & 0.58 \\
\hline Secondary & 27 & $0.70(0.20$ to 2.47$)$ & 0.29 \\
\hline $\begin{array}{l}\text { High school \& } \\
\text { diploma }\end{array}$ & 88 & $0.64(0.28$ to 1.48$)$ & 0.82 \\
\hline Job & & & 0.66 \\
\hline Employed & 13 & Ref & \\
\hline Housewife & 187 & 1.44 (0.27 to 7.63$)$ & \\
\hline \multicolumn{4}{|l|}{ Income } \\
\hline Inadequate & 23 & Ref & 0.29 \\
\hline Sufficient & 51 & $0.36(0.09$ to 1.30$)$ & 0.12 \\
\hline $\begin{array}{l}\text { Relatively } \\
\text { Adequate }\end{array}$ & 126 & 0.48 (0.15 to 1.51$)$ & 0.21 \\
\hline \multicolumn{4}{|l|}{ Spouse Education level } \\
\hline Collegiate & 6311 & Ref 0.51 (0.09 to 2.74$)$ & 0.82 \\
\hline Primary & & & 0.43 \\
\hline Secondary & 32 & $0.96(0.29$ to 3.19$)$ & 0.94 \\
\hline $\begin{array}{l}\text { High school \& } \\
\text { diploma }\end{array}$ & 94 & 0.77 (0.33 to 1.81$)$ & 0.55 \\
\hline
\end{tabular}

${ }^{\text {a }}$ Adjusted OR (95\%CI): adjusted odds ratio (95\% confidence interval).

of Tabriz University of Medical Science, assistance and cooperation of Arak University of Medical Science and personnel of health centers as well as the study participants, who patiently helped us in this research.

\section{Footnote}

Conflicts of Interest: The authors declare no conflicts of interest.

\section{References}

1. Tunzi M, Gray GR. Common skin conditions during pregnancy. Am Fam Phys. 2007;75(2).

2. Salter SA, Kimball AB. Striae gravidarum. Clin Dermatol. 2006;24(2):97-100. doi:10.1016/j.clindermatol.2005.10.008. [PubMed: $16487881]$. 
3. Cuningham FG, Bloom SL, Leveno KJ. Williams obstetrics. New York: Mc Graw Hill; 2010.

4. Cho S, Park ES, Lee DH, Li K, Chung JH. Clinical features and risk factors for striae distensae in Korean adolescents. J Eur Acad Dermatol Venereol. 2006;20(9):1108-13. doi: 10.1111/j.1468-3083.2006.01747.x. [PubMed: 16987267].

5. Sisson WR. Colored striae in adolescent children. J Pediatr. 1954;45(5):520-30. [PubMed: 13212593].

6. Atwal GS, Manku LK, Griffiths CE, Polson DW. Striae gravidarum in primiparae. Br J Dermatol. 2006;155(5):965-9. doi: 10.1111/j.13652133.2006.07427.x. [PubMed:17034526].

7. Davey CM. Factors associated with the occurrence of striae gravidarum. J Obstet Gynaecol Br Commonw. 1972;79(12):1113-4. [PubMed: 4646568].

8. Wong RC, Ellis CN. Physiologic skin changes in pregnancy. Semin Dermatol. 1989;8(1):7-11. [PubMed: 2701710].

9. Shuster S. The cause of striae distensae. Acta dermato-venereologica Supplementum. 1978;59(85):161-9.

10. Wade TR, Wade SL, Jones HE. Skin changes and diseases associated with pregnancy. Obstet Gynecol. 1978;52(2):233-42. [PubMed: 683665].

11. Osman H, Rubeiz N, Tamim H, Nassar AH. Risk factors for the development of striae gravidarum. Am J Obstet Gynecol. 2007;196(1):62 e1-5. doi:10.1016/j.ajog.2006.08.044. [PubMed: 17240237].

12. Thomas RG, Liston WA. Clinical associations of striae gravidarum. J Obstet Gynaecol. 2004;24(3):270-1. doi: 10.1080/014436104101001660779. [PubMed: 15203623].

13. McDaniel DH, Ash K, Zukowski M. Treatment of stretch marks with the 585-nm flashlamp-pumped pulsed dye laser. Dermatol Surg. 1996;22(4):332-7. [PubMed: 8624657].

14. Lerdpienpitayakul R, Manusirivithaya S, Wiriyasirivaj B, Lorwatthanasirikul J. Prevalence and risk factors of striae gravidarum in primiparae. Thai J Obstet Gynaecol. 2009;17:70-9.

15. Van den Bergh BR, Mennes M, Oosterlaan J, Stevens V, Stiers P, Marcoen A, et al. High antenatal maternal anxiety is related to impulsivity during performance on cognitive tasks in 14- and 15-year-olds. Neurosci Biobehav Rev. 2005;29(2):259-69. doi:10.1016/j.neubiorev.2004.10.010. [PubMed: 15811497].

16. Yamaguchi K, Suganuma N, Ohashi K. Quality of life evaluation in Japanese pregnant women with striae gravidarum: a cross- sectional study. BMC Res Notes. 2012;5:450. doi: 10.1186/1756-0500-5450. [PubMed: 22905939].

17. Pierard-Franchimont C, Hermanns JF, Hermanns-Le T, Pierard GE. Striae distensae in darker skin types: the influence of melanocyte mechanobiology.JCosmet Dermatol. 2005;4(3):174-8. doi: 10.1111/j.14732165.2005.00306.x. [PubMed: 17129262].

18. Lee SE, Kim JH, Lee SJ, Lee JE, Kang JM, Kim YK, et al. Treatment of striae distensae using an ablative 10,600-nm carbon dioxide fractional laser: a retrospective review of 27 participants. Dermatol Surg. 2010;36(11):1683-90. doi: 10.1111/j.1524-4725.2010.01719.x. [PubMed: 20840494].

19. Alster TS, Lupton JR. Prevention and treatment of side effects and complications of cutaneous laser resurfacing. Plast Reconstr Surg. 2002;109(1):308-16. [PubMed: 11786830] discussion 317-8.

20. Troisier E, Menetrier P. Histologie des vergetures. Ann Gynecol. 1889;31:206.

21. Alaiti S, Obagi ZE. Striae distensae. E Med J. 2001;1.

22. Brennan M, Young G, Devane D. Topical preparations for preventing stretch marks in pregnancy. Cochrane Database Syst Rev. 2012;11:CD000066. doi: 10.1002/14651858.CD000066.pub2. [PubMed: 23152199].

23. Poidevin LO. Striae gravidarum. Their relation to adrenal cortical hyperfunction. Lancet. 1959;2(7100):436-9. [PubMed: 14433675].

24. Souza E, Sorrells ME. Relationships among 70 North American oat germplasms: I. Cluster analysis using quantitative characters. Crop Sci. 1991;31(3):599-605.

25. Behnia $\mathrm{H}$, Hosseini $\mathrm{M}$. The protective effect of almond oil and glycerin in striae gravidarum. Pejouhandeh Q Res J. 2000;19:320-17.

26. Dhiman K, Sahoo M, Dhiman KS. A Clinical Study to Access the Efficacy of Karaveer Taila on Kikkisa (Striae Gravidarum). AYU. 2009;30(3):295.

27. Timur Tashan S, Kafkasli A. The effect of bitter almond oil and massaging on striae gravidarum in primiparaous women. J Clin Nurs. 2012;21(11-12):1570-6. doi: 10.1111/j.1365-2702.2012.04087.x. [PubMed: 22594386].

28. Taavoni S, Soltanipour F, Haghani H, Ansarian H, Kheirkhah M. Effects of olive oil on striae gravidarum in the second trimester of pregnancy. Complement Ther Clin Pract. 2011;17(3):167-9. doi: 10.1016/j.ctcp.2010.10.003. [PubMed: 21742284]. 